\title{
Synthesis and magnetic properties of a 1-D helical chain derived from a Nickel-Sodium Schiff base complex
}

\author{
APOORVA UPADHYAY ${ }^{\mathrm{a}}$, CHINMOY DAS ${ }^{\mathrm{a}}$, SHAIK NAGUL MEERA ${ }^{\mathrm{a}}$, \\ STUART K LANGLEY ${ }^{\mathrm{b}}$, KEITH S MURRAY ${ }^{\mathrm{b}}$ and MAHESWARAN SHANMUGAM ${ }^{\mathrm{a}, *}$ \\ a Department of Chemistry, Indian Institute of Technology Bombay, Powai, Mumbai, \\ Maharashtra 400 076, India \\ ${ }^{\mathrm{b}}$ School of Chemistry, University of Monash, Clayton, Victoria 3800, Australia \\ e-mail: eswar@chem.iitb.ac.in
}

MS received 29 April 2014; revised 6 June 2014; accepted 29 June 2014

\begin{abstract}
The reaction of the deprotonated form of the Schiff base ligand; (E)-2-methoxy-6-((phenylimino) methyl)phenol (L) with nickel chloride hydrate results in the formation of the 1-dimentional coordination polymer; $\mathrm{Na}\left[\mathrm{Ni}(\mathrm{L})_{2}(\mathrm{OMe})(\mathrm{MeOH})\right]_{\mathrm{n}}(\mathbf{1})$. The structure was determined via single crystal X-ray diffraction measurements. A careful analysis of the complex shows that the polymer exists as a helical structure, where the helicity is brought about by the presence of an alkali metal ion which is observed for the first time. Moreover the helical structure in $\mathbf{1}$ is maintained predominantly through covalent bond rather than supramolecular interactions. Direct current magnetic susceptibility measurement suggests that complex $\mathbf{1}$ obeys the Curie law. The fitting of magnetic data using the PHI software package yields parameters of $S=1, g=2.26$ and $D=+4.51$ (or $D=-7.24 \mathrm{~cm}^{-1}$ ) for $\mathbf{1}$.
\end{abstract}

Keywords. Nickel; Schiff base; magnetism; Helical chain.

\section{Introduction}

Helicity and chirality are the two most important features in biological process and are intimately associated with each other. In biological systems, L-amino acids and D-ribose molecules are the building blocks for the construction of $\alpha$-helical polypeptides and DNA, respectively. ${ }^{1-3}$ However, mimicking the biological system through coordination chemistry, particularly at the supramolecular level remains a demanding challenge for chemists as it is often difficult to predict the chirality and the helical nature of the product. ${ }^{4-11}$ Much attention has, however, still been drawn towards helical and chiral coordination complexes due to their fascinating structures, and the numerous potential applications such as molecular recognition, non-linear optical materials, asymmetric catalysis and enantiomorph separation. ${ }^{12-26}$ The ligand design is essential for the formulation of helical structures; with the use of enantiopure ligands along with specific transition metal ions allowing one to isolate the desired structures. ${ }^{17,27-29}$ Usually the chirality is transferred from the enantiopure ligand to the resultant helix, leading to the isolation of either right- $(\Delta)$ or left-handed $(\Lambda)$ helical structures. ${ }^{30-36}$ Precedents are known for the use of

*For correspondence achiral ligands with transition metal ions which will result in a racemic mixture of left and right handed helical structures or with small enantiomeric excess. ${ }^{37-41}$ Single stranded helical structures are the most commonly observed form compared to double and triple stranded structures, either with enantiopure or achiral ligands. The secondary structure of helical complexes is determined by weak metal-ligand covalent interactions, halide ions such as iodide and supramolecular interactions such as hydrogen bonding and $\pi-\pi$ stacking. ${ }^{42-47}$ It is well established in the literature of the formation of homometallic helical structures with transition metal ions such as $\mathrm{Ag}(\mathrm{I}), \mathrm{Fe}(\mathrm{III}), \mathrm{Ni}(\mathrm{II}), \mathrm{Cu}(\mathrm{II}){ }^{33,40,48-55}$ To the best of our knowledge, however, mixed metal ion helical structures have not been reported. In this line of interest we have reported the crystal structure of a helical complex containing octahedral $\mathrm{Ni}$ (II) ions with a Schiff base ligand, where the secondary structure was induced by an alkali metal ion and we have investigated its magnetic properties.

\section{Experimental}

Unless otherwise mentioned, all the reactions were carried out under aerobic condition. All the chemicals were purchased from commercially available sources 
(Alfa Aesar). The Schiff base ligand was synthesized as previously reported. ${ }^{56,57}$ The elemental analyses (CHN) were carried out on a Thermoquest microanalyser. Infrared spectra were collected for the solid samples using $\mathrm{KBr}$ pellets on a Perkin-Elmer FT-IR spectrometer between $400-4000 \mathrm{~cm}^{-1}$ range. Single crystal data were collected on a Rigaku Saturn CCD diffractometer $\left(\mathrm{MoK}_{\alpha}, \lambda=0.71073 \mathrm{~A}^{\circ}\right)$. The selected crystal was mounted on the tip of a glass pin using mineral oil and placed in the cold flow produced with an Oxford Cryocooling device. Complete hemispheres of data were collected by using $\omega$-scans $\left(0.3^{\circ}, 16 \mathrm{~s}\right.$ per frame). Integrated intensities were obtained with Rigaku Crystal Clear-SM Expert 2.1 software and they were corrected for absorption effects. Structure solution and refinement were performed with the SHELX-package. The structures were solved by direct methods and completed by iterative cycles of $\Delta \mathrm{F}$ syntheses and full-matrix leastsquares refinement against $F^{2}$. The magnetic measurement was carried out on a MPMS SQUID magnetometer equipped with 7.0 Tesla magnet. The magnetic data were fitted using PHI software. ${ }^{58}$

\subsection{Synthesis of complex 1}

The Schiff base ligand (E)-2-methoxy-6-((phenylimino)methyl)phenol) (HL) (1 g, $4.4 \mathrm{mmol})$ was dissolved in ethanol after which $\mathrm{NaOH}(1.1762 \mathrm{~g}, 4.4 \mathrm{mmol})$ was added and the resulting orange solution was stirred for ten minutes. Into this an ethanol solution of nickel chloride $(0.5235 \mathrm{~g}, 2.2 \mathrm{mmol})$ was then added dropwise. The colour of the solution slowly changed from orange to light green and the reaction mixture was stirred for 18 $\mathrm{h}$ at room temperature. After completion of the reaction, ethanol was evaporated under reduced pressure. Purification was performed by washing the crude mixture with water and cold pentane. The purified sample was recrystallized from $\mathrm{MeOH}$ and crystals suitable for X-ray diffraction were obtained after 4 days at low temperature $\left(5^{\circ} \mathrm{C}\right)$. Yield: $1.2 \mathrm{~g}(90 \%)$. IR ( $\mathrm{KBr}$ pellet): $1608 \mathrm{~cm}^{-1}\left(v-{ }_{\mathrm{C}=\mathrm{N}}\right)$. Elemental analysis (\%): exp: $\mathrm{C}=58.94, \mathrm{H}=5.09 \mathrm{~N}=4.96$; Cald: 59.11, $\mathrm{H}=5.60$, $\mathrm{N}=4.45$.

\section{Results and Discussion}

The reaction of the deprotonated ligand (L) and the nickel salt resulted in green single crystals (scheme 1). Single crystal X-ray diffraction measurements revealed that the complex is a 1-dimentional (1-D) coordination polymer of molecular formula $\mathrm{Na}\left[\mathrm{Ni}(\mathrm{L})_{2}(\mathrm{OMe})\right.$ $(\mathrm{MeOH})]_{\mathrm{n}}(\mathbf{1})$ (figure 1). It is found that complex $\mathbf{1}$,

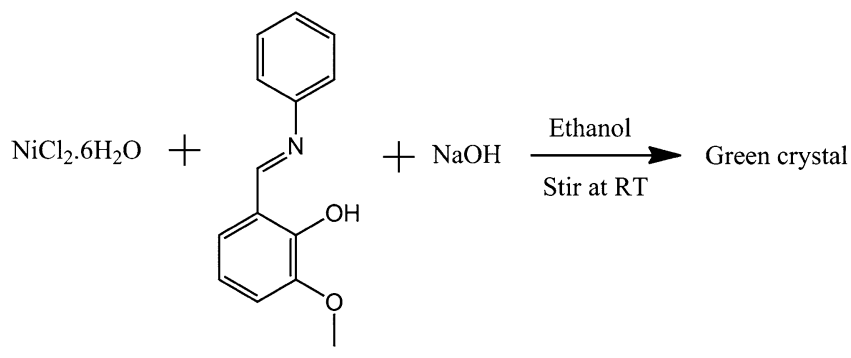

Scheme 1. General synthetic procedure followed for the isolation of complex $\mathbf{1}$.

crystallizes in monoclinic space group $C 2 / c$ and the crystallographic parameters are given in table 1 . The asymmetric unit consists of a $\mathrm{Ni}(\mathrm{II}), \mathrm{Na}(\mathrm{I})$, two Schiff base, methoxy and methanol ligands. The divalent nickel ion displays a distorted octahedral geometry and is coordinated by the two deprotonated Schiff base ligands. Two phenolate oxygen- and two imine nitrogenatoms make up four of the coordination sites. The final two sites are accomplished by a methoxy group (O61) and a methanol solvent molecule (O51). The assignment of methanol and methoxy ligand is based on the bond length parameters (as it is difficult to find out the fourier peak for the hydrogen in X-ray) where the later coordinated ligand possesses slightly longer bond length $(2.168 \AA)$ than the former $(2.156 \AA)$. The average Ni1-O and Ni1-N bond distances are found to be $2.0735 \AA$ and $2.074 \AA$ respectively, consistent with that of other $\mathrm{Ni}$ (II) complexes. ${ }^{59,60}$ The $\mathrm{Na}(\mathrm{I})$ ion present in six coordinate environment, which is stabilized by covalent interactions provided by the Schiff base methoxy and phenolate groups, as well as the methoxide and methanol ligands, with an average Na1-O bond length of $2.8055 \AA$. The phenoxy groups of L, the methanol (O51) and the methoxide ligands (O61) provides a linkage between the $\mathrm{Ni}$ (II) and the sodium ion with the (Ni1-O51-Na1) angle being $109.3^{\circ}$ and (Ni1-O11-Na1) angle being $106.9^{\circ}$. In the crystal structure, the $\mathrm{Na}^{+}$ion resides in a special position, which is responsible for the 1-D extended structure. Analysis of the crystal structure of complex 1 reveals that it exists as a single stranded helical structure (figure 1). Also, by considering the overall metal arrangement, sodium and nickel ion are arranged in a zigzag manner. Existence of both zigzag nature and helical structure is very rare. Helical structures with Schiff base ligands like L are unusal. However, single stranded helical structures are common with other ditopic ligands, either through covalent or supramolecular interactions. ${ }^{61-65}$ Furthermore, there is not only precedent for single stranded helical complexes, but also for double or even triple stranded helical structres with specifically designed flexible Schiff base ligands or with flexible 

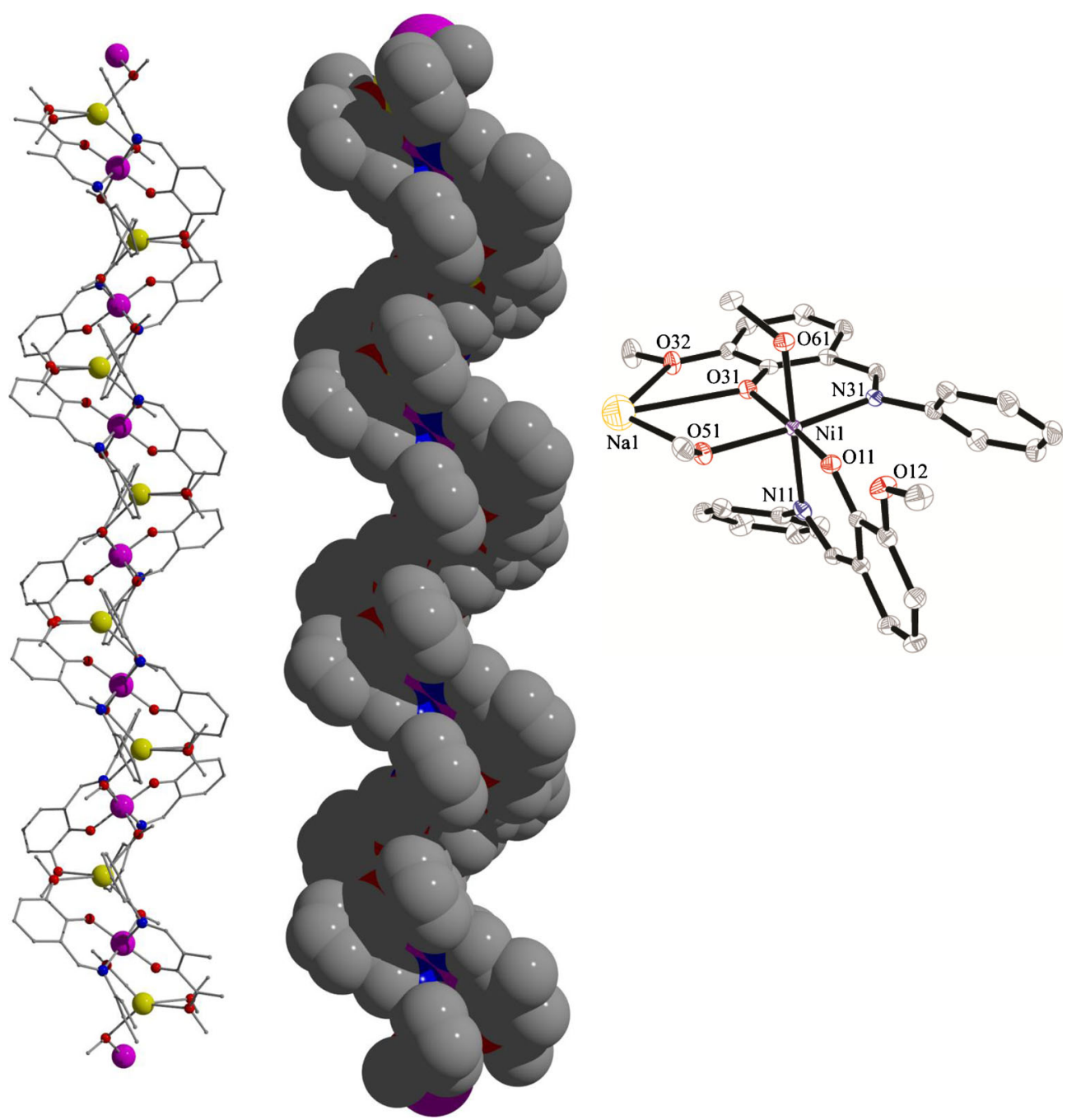

Figure 1. a) Ball and stick representation of crystal structure of complex 1 (left) B) space filling model of crystal structure of $\mathbf{1}$ (middle). C) Thermal ellipsoid structure of repeating unit found in complex 1. Hydrogen atoms are omitted for clarity. Colour code: Magenta $=$ $\mathrm{Ni}(\mathrm{II})$; Yellow $=\mathrm{Na}$; Red $=\mathrm{O}$; Blue $=\mathrm{N}$; grey $=\mathrm{C}$.

amide functionalities. ${ }^{63,66-71}$ Supramolecular interactions offered by these functionalities are the essential ingredients that are indispensable for the unusual double-helical or triple helical structures. ${ }^{61,72-77}$

The most common single stranded helical structures are induced predominantly by ligand design and through metal-ligand covalent interactions, hydrogen bonding, $\pi-\pi$ stacking and argentophilic interactions. Recently, an iodine assisted helical structure has also been reported. ${ }^{78}$ To our surprise, both intra and intermoelcular supramolecular interactions such as hydrogen bonding or $\pi-\pi$ interactions are absent in the packing arrangement of $\mathbf{1}$, an uncommon outcome. Moreover the Schiff base ligand employed in the reaction does not possess any flexible spacer which is often responsible for the helical nature of many complexes. $^{39,79-82}$ These scenarios clearly emphasize that the helical nature of the complex $\mathbf{1}$ is purely due to metal-covalent interactions and the alkali ion present in the crystal lattice plays a significant role. To the best of our knowledge, alkali metal ion induced helicity is observed for the first time as opposed to other cases where homometallic transition metal complexes stimulate the helicity in the structure.

It is well understood that when achiral ligands are used for the design of helical structures, the resultant complex is isolated as a racemic mixture i.e., a 50:50 mixture of left and right handed helical structures. As expected for 1, it is found that 1-D helical chains of left and right handed configurations arrange in an alternate manner. From the crystal packing diagram (figure 2), we can clearly see the helical chains are arranged along the b-axis and there are no significant intermolecular interactions between the chains (closest $\mathrm{Ni}$ (II)-Ni(II) 
Table 1. Crystallographic parameters for complex $\mathbf{1}$.

\begin{tabular}{ll}
\hline & $\mathbf{1}$ \\
\hline Formula & $\mathrm{C}_{30} \mathrm{H}_{31} \mathrm{~N}_{2} \mathrm{Na}_{1} \mathrm{NiO}_{6}$ \\
Size & $0.570 \times 0.560 \times 0.130$ \\
System & Monoclinic \\
Space group & $C 2 / c$ \\
$a[\AA]$ & $28.669(6)$ \\
$b[\AA]$ & $12.460(3)$ \\
$c[\AA]$ & $16.680(3)$ \\
$\beta\left[{ }^{\circ}\right]$ & $110.61(3)$ \\
$V\left[\AA^{3}\right]$ & $5576.9(19)$ \\
$\mathrm{Z}$ & 8 \\
$\rho_{\text {calcd }}$ [g/cm & \\
$\left.2 \theta_{\text {max }}\right]$ & 1.420 \\
Radiation & 52.74 \\
$\lambda[\AA]$ & $\mathrm{MoK}$ \\
$T[\mathrm{~K}]$ & 0.71073 \\
Reflns & $100(2)$ \\
Ind. Reflns & 34401 \\
Reflns with $>2 \sigma(\mathrm{I})$ & 5535 \\
R1 & 5053 \\
wR2 & 0.0524 \\
\hline
\end{tabular}

distance $9.27 \AA$ ). Moreover, the enantiomers of $\mathbf{1}$ are not direct mirror images of one another, one isomer (either left or right handed) is however, translated into space along the c-axis with mirror reflection leading to a close packing arrangement that in turn results in the non-availability of voids in the structure (figure 3 ). Unlike the situtation here, there are several reports where the helical chain arrangement leads to a large void space, which is used for accommodating solvent molecules. ${ }^{83-89}$

Although several characterization methods have been reported, magnetic properties for these helical structures are very scarce in the literature..$^{8,71,90-96}$ Direct current magnetic susceptibility measurements were performed on a polycrystalline sample of $\mathbf{1}$, with an applied magnetic field of 0.5 Tesla, between $2-300 \mathrm{~K}$ (figure 4). The room temperature $\chi_{M} T$ value of $1.285 \mathrm{~cm}^{3} \mathrm{~K} \mathrm{~mol}^{-1}$ is slightly higher than the spin only value of $1.0 \mathrm{~cm}^{3} \mathrm{~K} \mathrm{~mol}^{-1}$ with an average $g$-value of 2.0. The $\chi_{M} T$ value remains constant from room temperature down to $15.0 \mathrm{~K}$. This temperature independent behaviour emphasizes that the $\mathrm{Ni}$ (II) ion behaves as a simple paramagnet (figure 5), which is conceivable due to the closest $\mathrm{Ni}$ (II)-Ni(II) distance within the chain being $7.68 \AA$. However, the $\chi_{M} T$ value drops steeply, below $15.0 \mathrm{~K}$, which could be due to the magnetic anisotropy, Zeeman depopulation effect and/or antiferromagnetic intermolecular interactions. The later contribution is unlikely due to the longer $\mathrm{Ni}(\mathrm{II})$ distance found between the chains of $9.28 \AA$ and the absence of any solvate molecules in the crystal lattice which are often responsible for intermolecular antiferromagnetic interactions through dipolar interactions.

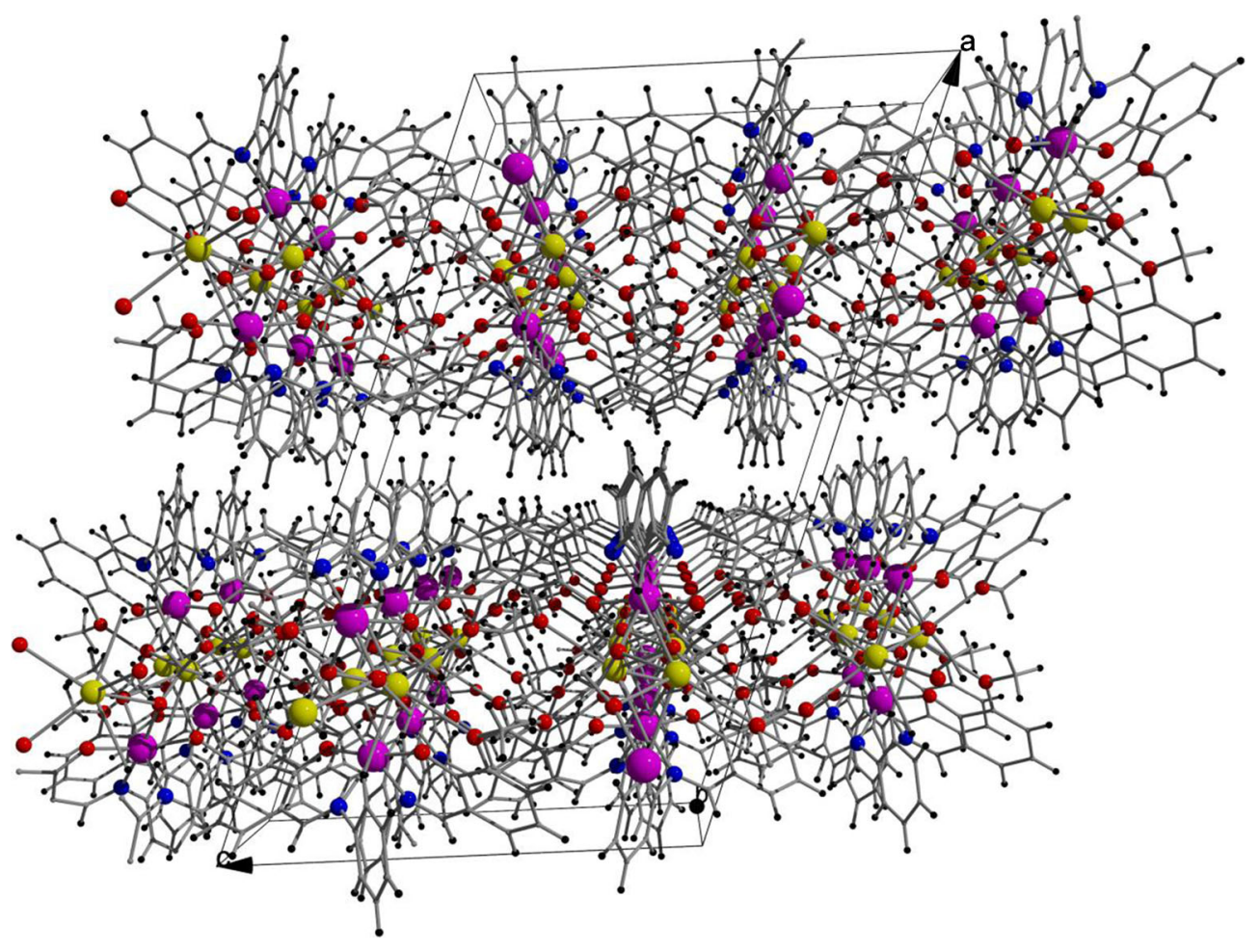

Figure 2. Packing diagram of complex $\mathbf{1}$. 


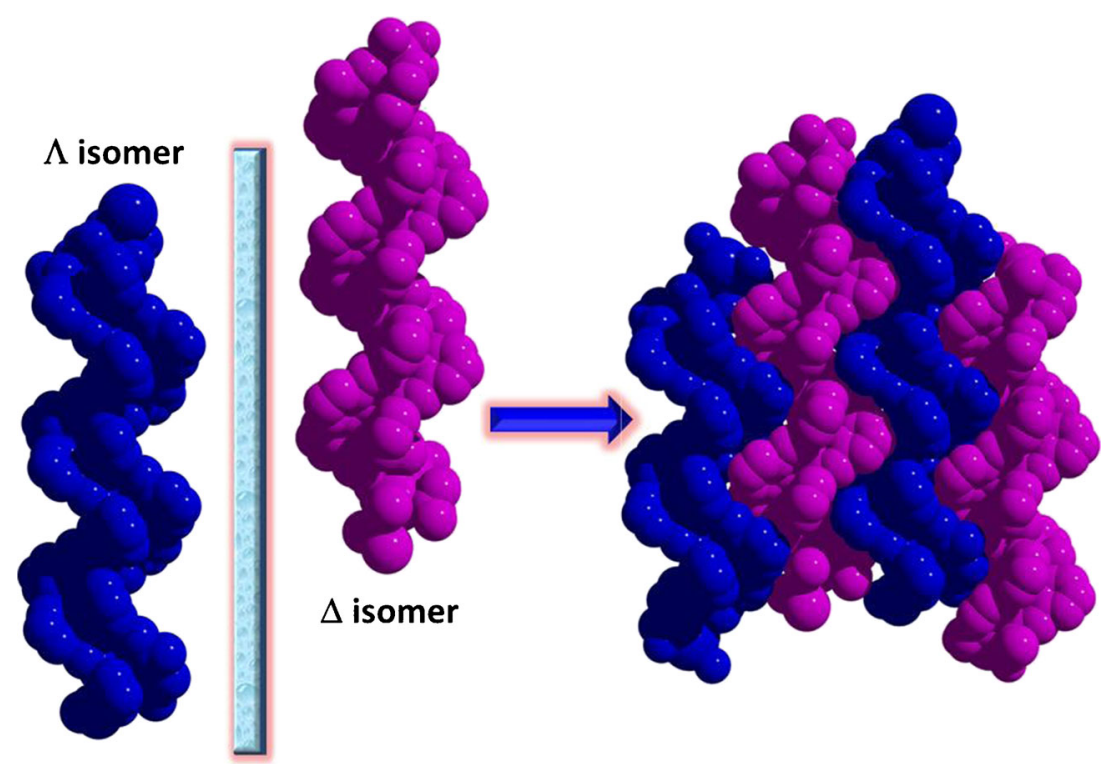

Glide plane

Figure 3. Space filling models of $\Lambda$ which is reflected and translated in space (glide plane) leads to $\Delta$ isomers of $\mathbf{1}$ and its crystal packing shows that there are no void space available to accommodate solvent molecules.

In order to extract the Spin Hamiltonian (SH) parameters, the magnetic data was fitted using the PHI software package. An excellent fit of the experimental data (figure 4) resulted in the following parameters; $S=1$, $g=2.26, D=+4.51 \mathrm{~cm}^{-1}$. The fitting however is insensitive to sign of $D$ and a fit can also be obtained with $S=1 \mathrm{~g}=2.26, D=-7.24 \mathrm{~cm}^{-1}$. In order to determine whether easy plane or easy axis anisotropy operates in $\mathbf{1}$, further spectroscopic measurements such as EPR, single crystal measurement (to extract $\chi_{x}, \chi_{y}$, and $\left.\chi_{z}\right)$ and MCD are required. These studies are currently

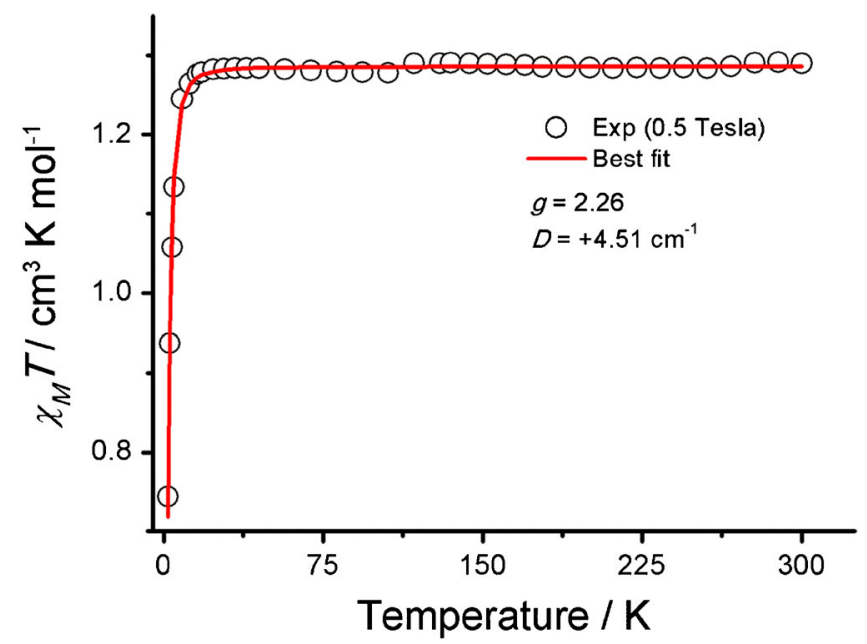

Figure 4. Temperature dependent $\chi_{M} T$ versus $T$ plot of polycrystalline sample of $\mathbf{1}$ measured at the indicated external field. The red solid line represents the best fit obtained and the SH parameters obtained are listed. under progress. Therefore, complex 1 possesses an $S=$ 1 ground state with a $g$ value of 2.26 , similar to that of previously reported $\mathrm{Ni}(\mathrm{II})$ complexes. ${ }^{97-100}$

\section{Conclusion}

We have reported a novel single stranded helical chain consisting of $\mathrm{Ni}(\mathrm{II})$ and $\mathrm{Na}(\mathrm{I})$ ions,

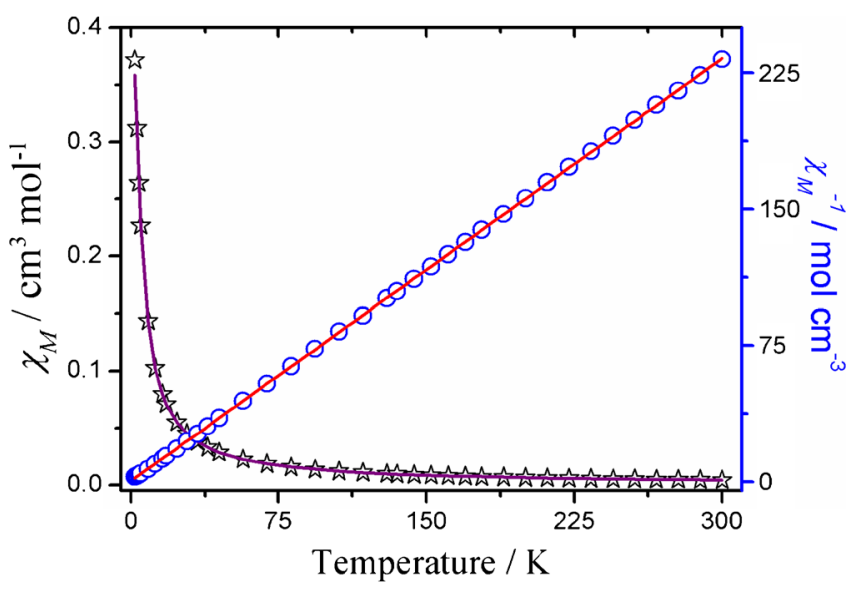

Figure 5. Temperature dependent $\chi_{M}$ versus $T$ plot of polycrystalline sample of 1 measured at 0.5 Tesla (open star). The solid purple line represents the best fit obtained using the parameters discussed in the main text. Inverse susceptibility versus temperature (open circle) plot of complex 1 emphasize the paramagnetic nature of $\mathrm{Ni}(\mathrm{II})$ in $\mathbf{1}$. Solid line represents a linear fit (red line) between $300 \mathrm{~K}$ to $2.0 \mathrm{~K}$ which goes closer to the origin (intercept $=0.3$ ). 
with the Schiff base ligand (E)-2-methoxy-6((phenylimino)methyl)phenol). The structure of the complex was determined via X-ray diffraction measurements. The crystal lattice contains both left and right handed helical structures with equal probability; hence the resultant structure is racemic in nature. The involvement of sodium ion in determining the secondary structure of $\mathbf{1}$ is observed for the first time. Investigation of the magnetic properties of $\mathbf{1}$ reveals that the intramolecular super-exchange interactions are negligible, implying that the nickel ion behaves like a simple paramagnet. The SH parameters obtained by fitting the magnetic data $\left(S=1, g=2.26\right.$ and $D=+4.51 \mathrm{~cm}^{-1}$ (or $\mathrm{D}=-7.24 \mathrm{~cm}^{-1}$ )) clearly suggest that the $\mathrm{Ni}(\mathrm{II})$ ion possess significant anisotropy. To determine the $D$ value quantitatively, further spectroscopic investigations are required which will be carried out and communicated in near future.

\section{Supplementary Information}

The cif file for the complex $\mathbf{1}$ is given in the ESI. CCDC number: 999644. Supplementary information is available at www.ias.ac.in/chemsci.

\section{Acknowledgements}

MS thanks the funding agencies Department of Science and Technology (DST) (SR/S1/IC-32/2011), DST nanomission (SR/NM/NS-1119/2011) and IIT Bombay for financial support. KSM acknowledges the support of an Australia-India AISRF grant. We thank Dr. B Moubaraki for experimental assistance. AU acknowledges CSIR for financial support.

\section{References}

1. Nakano T and Okamoto Y 2001 Chem. Rev. 1014013

2. Pauling L, Corey R B and Branson H R 1951 Proc. Natl. Acad. Sci. U. S. A. 37205

3. Watson J D and Crick F H C 1953 Nature 171737

4. Chen N, Li M-X, Yang P, He X, Shao M and Zhu S-R. 2013 Cryst. Growth Des. 132650

5. Chen Z, Qin S, Liu D, Shen Y and Liang F 2013 Cryst. Growth Des. 133389

6. He W-W, Yang J, Yang Y, Liu Y-Y and Ma J-F 2012 Dalton Trans. 419737

7. Kano K and Hasegawa H 2001 J. Am. Chem. Soc. 123 10616

8. Lu W-G, Gu J-Z, Jiang L, Tan M-Y and Lu T-B 2008 Cryst. Growth Des. 8192

9. Wen L-L, Dang D-B, Duan C-Y, Li Y-Z, Tian Z-F and Meng Q-J 2005 Inorg. Chem. 447161
10. Xiao D-R, Wang E-B, An H-Y, Li Y-G, Su Z-M and Sun C-Y 2006 Chem. Eur. J. 126528

11. Zahn S and Canary J W 2000 Science 2881404

12. Cui Y, Evans O R, Ngo H L, White P S and Lin W 2002 Angew. Chem. Int. Ed. 411159

13. Deuss P J, den Heeten R, Laan W and Kamer P C J 2011 Chem. Eur. J. 174680

14. Evans O R and Lin W 2001 Chem. Mater. 133009

15. Hou H, Meng X, Song Y, Fan Y, Zhu Y, Lu H, Du C and Shao W 2002 Inorg. Chem. 414068

16. Hou H, Wei Y, Song Y, Zhu Y, Li L and Fan Y $2002 J$. Mater. Chem. 12838

17. Kathalikkattil A C, Bisht K K, Aliaga-Alcalde N and Suresh E 2011 Cryst. Growth Des. 111631

18. Kitagawa S, Kitaura R and Noro S-i 2004 Angew. Chem. Int. Ed. $\mathbf{4 3} 2334$

19. Kondo M, Miyazawa M, Irie Y, Shinagawa R, Horiba T, Nakamura A, Naito T, Maeda K, Utsuno S and Uchida F 2002 Chem. Commun. 2156

20. Lee S J, Hu A and Lin W 2002 J. Am. Chem. Soc. 124 12948

21. Lin W, Wang Z and Ma L 1999 J. Am. Chem. Soc. 121 11249

22. Meng X, Song Y, Hou H, Fan Y, Li G and Zhu Y 2003 Inorg. Chem. 421306

23. Seo J S, Whang D, Lee H, Jun S I, Oh J, Jeon Y J and Kim K 2000 Nature 404982

24. Trindade A F, Gois P M P and Afonso C A M 2009 Chem. Rev. (Washington, DC, U. S.) 109418

25. Zhang J, Chen S, Wu T, Feng P and Bu X $2008 \mathrm{~J}$. Am. Chem. Soc. 13012882

26. Zhang Q, Bu X, Lin Z, Biasini M, Beyermann $\mathrm{W}$ and Feng P 2007 Inorg. Chem. 467262

27. Biswas C, Drew M G B, Estrader M and Ghosh A 2009 Dalton Trans. 5015

28. Lin F, Peng H-Y, Chen J-X, Chik D T W, Cai Z, Wong K M C, Yam V W W and Wong H N C $2010 \mathrm{~J}$. Am. Chem. Soc. 13216383

29. Prema D, Oshin K, Desper J and Levy C J 2012 Dalton Trans. 414998

30. Anokhina E V and Jacobson A J 2004 J. Am. Chem. Soc. 1263044

31. Anthony S P and Radhakrishnan T P 2004 Chem. Commun. 1058

32. Heo J, Jeon Y-M and Mirkin C A 2007 J. Am. Chem. Soc. 1297712

33. Jiang L, Feng X-L, Su C-Y, Chen X-M and Lu T-B 2007 Inorg. Chem. 462637

34. Jiang L, Lu T-B and Feng X-L 2005 Inorg. Chem. 44 7056

35. Ohrstrom L, Larsson K, Borg S and Norberg S T 2001 Chem. Eur. J. 74805

36. Roth A, Koth D, Gottschaldt M and Plass W 2006 Cryst. Growth Des. 62655

37. Isfort C S, Kreickmann T, Pape T, Froehlich R and Hahn F E 2007 Chem. Eur. J. 132344

38. Kim H-J, Lee E, Park H-S and Lee M 2007 J. Am. Chem. Soc. 12910994

39. Wang R, Zhou Y, Sun Y, Yuan D, Han L, Lou B, Wu B and Hong M 2005 Cryst. Growth Des. 5251

40. Wu S-T, Wu Y-R, Kang Q-Q, Zhang H, Long L-S, Zheng Z, Huang R-B and Zheng L-S 2007 Angew. Chem. Int. Ed. $\mathbf{4 6} 8475$ 
41. Zhang Y, Li J, Chen J, Su Q, Deng W, Nishiura M, Imamoto T, Wu X and Wang Q 2000 Inorg. Chem. 39 2330

42. Delsuc N, Godde F, Kauffmann B, Leger J-M and Huc I 2007 J. Am. Chem. Soc. 12911348

43. Dumitru F, Legrand Y-M, Van der Lee A and Barboiu M 2009 Chem. Commun. 2667

44. Hu H-Y, Xiang J-F, Yang Y and Chen C-F 2008 Org. Lett. 101275

45. Sun Q, Bai Y, He G, Duan C, Lin Z and Meng Q 2006 Chem. Commun. 2777

46. Xiao D-R, Wang E-B, An H-Y, Li Y-G and Xu L 2007 Cryst. Growth Des. 7506

47. Xiao J, Xu J, Cui S, Liu H, Wang S and Li Y 2008 Org. Lett. 10645

48. Wen H-R, Wang C-F, Li Y-Z, Zuo J-L, Song Y and You $\mathrm{X}-\mathrm{Z} 2006$ Inorg. Chem. 457032

49. Zheng X-D, Jiang L, Feng X-L and Lu T-B 2008 Inorg. Chem. 4710858

50. Goetz S and Kruger P E 2006 Dalton Trans. 1277

51. Keegan J, Kruger P E, Nieuwenhuyzen M, O'Brien J and Martin N 2001 Chem. Commun. 2192

52. Piguet C, Bernardinelli G, Bocquet B, Quattropani A and Williams A F 1992 J. Am. Chem. Soc. 1147440

53. Piguet C, Bernardinelli G and Williams A F 1989 Inorg. Chem. 282920

54. Provent C, Hewage S, Brand G, Bernardinelli G, Charbonniere L J and Williams A F 1997 Angew. Chem., Int. Ed. Engl. 361287

55. Tynan E, Jensen P, Kelly N R, Kruger P E, Lees A C, Moubaraki B and Murray K S 2004 Dalton Trans. 3440

56. Upadhyay A, Komatireddy N, Ghirri A, Tuna F, Langley S K, Srivastava A K, Sanudo E C, Moubaraki B, Murray K S, McInnes E J L, Affronte M and Shanmugam M 2014 Dalton Trans. 43259

57. Upadhyay A, Vaidya S, Venkatasai V S, Jayapal P, Srivastava A K, Shanmugam M and Shanmugam M 2013 Polyhedron 6687

58. Chilton N F, Anderson R P, Turner L D, Soncini A and Murray K S 2013 J. Comput. Chem. 341164

59. Schwarzenbach G, Buergi H B, Jensen W P, Lawrance G A, Moensted L and Sargeson A M 1983 Inorg. Chem. 224029

60. Zeller A, Herdtweck E and Strassner T 2004 Inorg. Chem. Commun. 7296

61. Luan X-J, Wang Y-Y, Li D-S, Liu P, Hu H-M, Shi Q-Z and Peng S-M 2005 Angew. Chem.Int. Ed. 443864

62. Plasseraud L, Maid H, Hampel F and Saalfrank R W 2001 Chem. Eur. J. 74007

63. Qi Y, Luo F, Batten S R, Che Y-X and Zheng J-M 2008 Cryst. Growth Des. 82806

64. Zhang J, Chen S, Zingiryan A and Bu X 2008 J. Am. Chem. Soc. 13017246

65. Zhang S, Yang S, Lan J, Yang S and You J 2008 Chem. Commun. 6170

66. Cordes D B, Sharma C V K and Rogers R D 2007 Cryst. Growth Des. 71943

67. Flores-Lopez, L Z, Parra-Hake M, Somanathan R and Walsh P J 2000 Organometallics 192153

68. Lalehzari A, Desper J and Levy C J 2008 Inorg. Chem. 471120

69. Li X-Z, Hao P-P, Wang D and Zhu L-N 2013 Cryst. Eng. Comm. 152800
70. Telfer S G, Sato T, Harada T, Kuroda R, Lefebvre J and Leznoff D B 2004 Inorg. Chem. 436168

71. Zheng X-D, Jiang L, Feng X-L and Lu T-B 2009 Dalton Trans. 6802

72. Byrne P, Lloyd G O, Anderson K M, Clarke N and Steed J W 2008 Chem. Commun. 3720

73. Han L, Valle H and Bu X 2007 Inorg. Chem. 461511

74. Ikeda M, Tanaka Y, Hasegawa T, Furusho Y and Yashima E 2006 J. Am. Chem. Soc. 1286806

75. Jouaiti A, Hosseini M W and Kyritsakas N 2003 Chem. Commun. 472

76. Lehn J M, Rigault A, Siegel J, Harrowfield J, Chevrier B and Moras D 1987 Proc. Natl. Acad. Sci. U. S. A. 84 2565

77. Zhang W, Wang Z-Q, Sato O and Xiong R-G 2009 Cryst. Growth Des. 92050

78. Zhang F, Yajima T, Li Y-Z, Xu G-Z, Chen H-L, Liu Q-T and Yamauchi O 2005 Angew. Chem. Int. Ed. 44 3402

79. Biradha K and Fujita M 2002 Angew. Chem. Int. Ed. 413392

80. Carlucci L, Ciani G, Proserpio D M and Sironi A 1995 Angew. Chem.Int. Ed. Engl. 341895

81. Carlucci L, Cozzi N, Ciani G, Moret M, Proserpio D M and Rizzato S 2002 Chem. Commun. 1354

82. Fujita M, Kwon Y J, Washizu S and Ogura K 1994 J. Am. Chem. Soc. 1161151

83. Bartual-Murgui C, Salmon L, Akou A, Ortega-Villar N A, Shepherd H J, Munoz M C, Molnar G, Real J A and Bousseksou A 2012 Chem. Eur. J. 18507

84. Dey R, Haldar R, Maji T K and Ghoshal D 2011 Cryst. Growth Des. 113905

85. Hawes C S and Kruger P E 2013 Polyhedron 52255

86. Li X, Cai Y, Fang Z, Wu L, Wei B and Lin S 2011 Cryst. Growth Des. 114517

87. Li Y and Shi J 2014 Adv. Mater. Ahead of Print

88. Meng F, Qin L, Zhang M and Zheng H 2014 Cryst. Eng. Comm. 16698

89. Zhang G, Yang G and Ma J S 2006 Cryst. Growth Des. 6375

90. Huang Y-Q, Zhao X-Q, Shi W, Liu W-Y, Chen Z-L, Cheng P, Liao D-Z and Yan S-P 2008 Cryst. Growth Des. 83652

91. Kar P, Biswas R, Drew M G B, Ida Y, Ishida T and Ghosh A 2011 Dalton Trans. 403295

92. Shova S, Novitchi G, Gdaniec M, Caneschi A, Gatteschi D, Korobchenko L, Voronkova V K, Simonov Y A and Turta C 2002 Eur. J. Inorg. Chem. 3313

93. Wen H-R, Wang C-F, Song Y, Zuo J-L and You X-Z 2005 Inorg. Chem. 449039

94. Zheng X-D, Hua Y-L, Xiong R-G, Ge J-Z and Lu T-B 2011 Cryst. Growth Des. 11302

95. Charbonniere L J, Williams A F, Piguet C, Bernardinelli G and Rivara-Minten E 1998 Chem. Eur. J. 4485

96. Tuna F, Lees M R, Clarkson G J and Hannon M J 2004 Chem. - Eur. J. 105737

97. Boca R 2004 Coord. Chem. Rev. 248757

98. Carlin R L, O'Connor C J and Bhatia S H 1976 J. Am. Chem. Soc. 983523

99. Pardi L A, Hassan A K, Hulsbergen F B, Reedijk J, Spek A L and Brunel L-C 2000 Inorg. Chem. 39159

100. Rogez G, Rebilly J-N, Barra A-L, Sorace L, Blondin G, Kirchner N, Duran M, van Slageren J, Parsons S, Ricard L, Marvilliers A and Mallah T 2005 Angew. Chem.Int. Ed. 441876 